\title{
Detection and quantification of adverse events associated with the insertion and replacement of short peripheral vascular catheters through a Check List in areas of Medical Clinic Hospitalization.
}

July 2016 to December 2017.

Alvarez,C1; Fonseca,V²; Brandan,V3; Sandoval,M4; Ledezma,F5; Reque,C6; Esquivel,M7\%; Dell,M8;Parino, E9;Pisapia,J10; Vidiella,G11. Clínica y Maternidad Suizo Argentina. Bs As. Argentina.

Introduction: More than 1 million $\left(10^{6}\right)$ short PVCs are placed in hospitalized patients ${ }^{1}$.The overall incidence rate of phlebitis is $10 \%{ }^{3}$ This study is based on the increase of thrombophlebitis, phlebitis, infiltrations and obstructions cases in patients hospitalized with a PVC in clinical sectors, using a checklist for the insertion of the PVC.

Material and Methods:1) A registration sheet (e.g. Checklist) to record data on insertion, daily monitoring and PVC replacement. Population: Patients with PVC hospitalized in CyMSA Adult Section Study: Detailed, cross-sectional observational study. Period: July 2016 - December 2017

Results: 974 PTFE (Polytetrafluoroenthylene) PVCs and 636 pre-assembled closed IV catheters (NEXIVA) were inserted. Patients' age: 19-104 years. In total, 1,610 Checklist records were made for PVC insertion and replacement.(Chart No.1). 18 cases of Thrombophlebitis(TBP) were recorded and assessed by the clinician. 1/18 TBP was considered to be superinfected, without microorganism recovery in the forearm of URE. All patients extended their hospitalization due to their phlebitis. Age ranged from 38 to 94 years old, 11/18 women. 4/18 required further tests, e.g. Doppler ultrasound of the limb affected. All patients received physical treatment and were administered antimicrobial drugs for the superinfected TBP. Adverse events were: 559/1610, (34.72\%). The most used (497) short PVC site is the upper right arm and the left arm/ hand. Gauge No. 20

Discussion: There is insufficient evidence for the recommendation to use a checklist of short PVC insertion consistently. $20 \%$ global prevalence of chemical phlebitis was high compared to the expected rate.

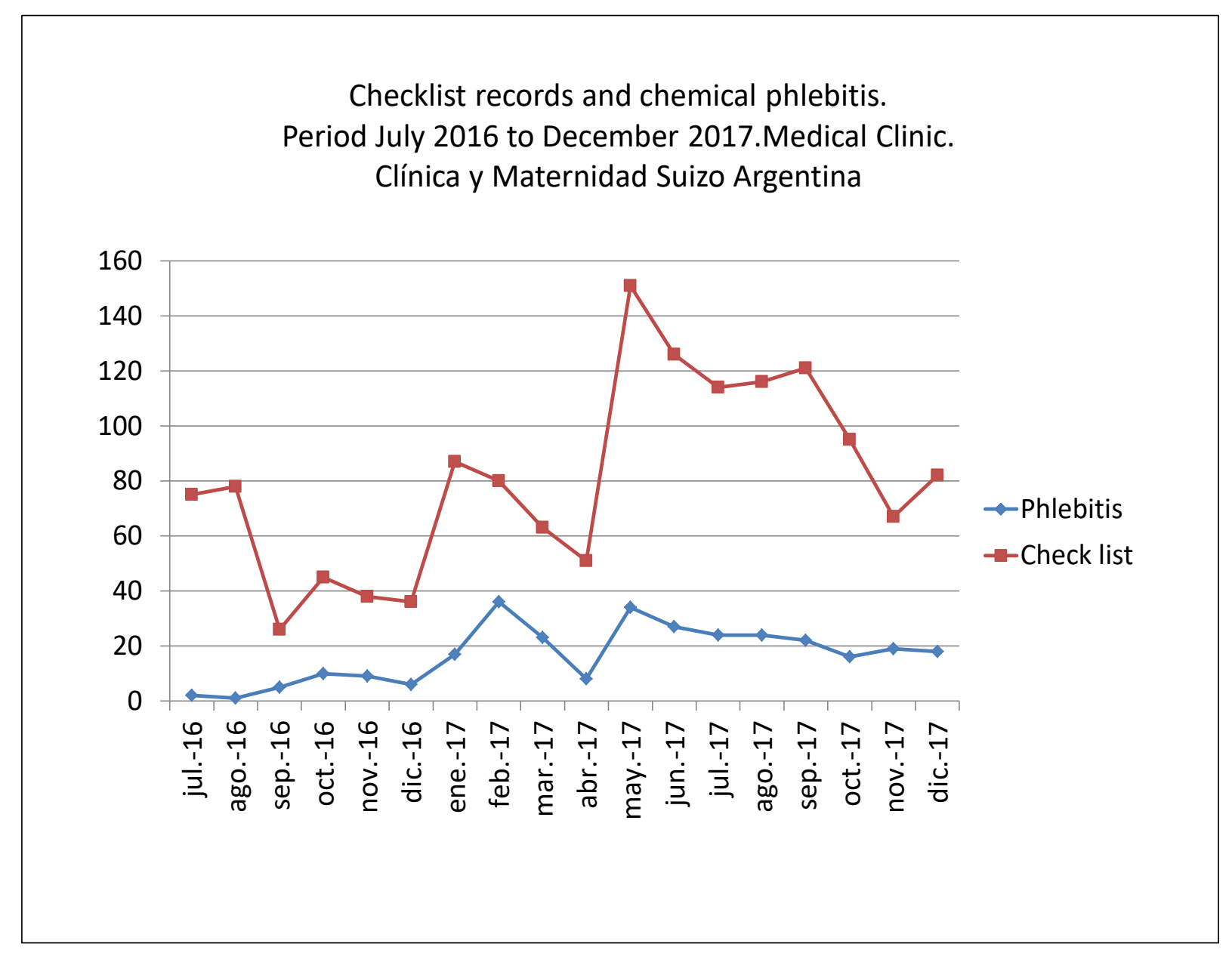

\begin{tabular}{|c|c|c|c|}
\hline Tipe of Event & $\begin{array}{l}\text { Total } \\
\text { Short } \\
\text { PVA }\end{array}$ & $\begin{array}{l}\text { Adverse } \\
\text { events by } \\
\text { type of } \\
\text { supplies }\end{array}$ & $\begin{array}{c}\text { Results } \\
\text { obtained }\end{array}$ \\
\hline CHEMICAL PHLEBITIS & 1610 & 322 & $20 \%$ \\
\hline $\begin{array}{l}\text { Phlebitis caused by PTFE catheter. } \\
\text { (Polytetrafluoroethylene) }\end{array}$ & 974 & 278 & $28,54 \%$ \\
\hline $\begin{array}{l}\text { Phlebitis caused by pre-assembled } \\
\text { closed IV catheter system. } \\
\text { PCS.(NEXIVA) }\end{array}$ & 636 & 44 & $6,91 \%$ \\
\hline INFILTRATIONS & 1610 & 164 & $10,19 \%$ \\
\hline PTFE & 974 & 115 & 11,80 \\
\hline NEXIVA.PCS & 636 & 49 & $7,70 \%$ \\
\hline OCCLUSIONS & 1610 & 73 & $4,53 \%$ \\
\hline PTFE & 974 & 51 & $5,23 \%$ \\
\hline NEXIVA.PCS & 636 & 22 & $3,45 \%$ \\
\hline GLOBAL EVENTS. (Chart na ${ }^{\mathrm{a}}$ ) & 1610 & 559 & $34,72 \%$ \\
\hline $\begin{array}{l}\text { OMG PIVC (One Million Global } \\
\text { Catheter PIVC Worldwide Prevalence } \\
\text { Study) } 2014\end{array}$ & & & $10 \%$ \\
\hline
\end{tabular}

Conclusion: The checklist is a tool that enabled to demonstrate and systematize the record of adverse events associated with short PVC, throughout the study. Based on this study, some strategies were recommended, such as the insertion of a PICC catheter for the infusion of vesicant solutions for more than 4 days, among other measures, to reduce adverse events. Add a liaison nurse to the team, to carry out the active surveillance of VA, daily records, data analysis and tabulation. Continue with the formal and incidental training of all nursing personnel from the different shifts.

Train the personnel in charge of site operations for event recording and daily reports to risk and infection control service. Carry out an on-going evaluation of the different medical devices used in such processes, along with nursing, pharmacy and infection control.

Bibliography: ${ }^{1}$ PRNewswire. (2014). Global Peripheral I.V. Catheter Market 2014-2018. Terapia de infusión Normas de la práctica- INS 2016; pag, 91-93.3) 